\title{
Hepatitis B in the Middle East: aspects of epidemiology and liver disease after infection
}

\author{
A U Toukan
}

\begin{abstract}
Postnatal horizontal transmission of hepatitis B virus (HBV) in early childhood seems to be the predominant method by which high hepatitis $B$ carrier rates in the Middle East are maintained. The prevalence of hepatitis $B$ surface antigen (HBsAg) positive status among siblings of HBV carriers is similar during childhood and adulthood, suggesting that childhood intrafamilial transmission patterns persist into adult life. There is a tendency for asymptomatic HBV carriers to have higher alanine aminotransferase (ALT) values, a feature that also tends to cluster in families. Infection in the first five years of life contributes most to the case load of chronic liver disease and thus to mortality from HBV. Mass hepatitis B immunisation programmes have been started, and while they may eventually reduce the $\mathrm{HBV}$ carrier state and liver disease loads significantly, prospects for total eradication of $\mathrm{HBV}$ in the near future are not good.

(Gut 1996; 38 (suppl 2): S2-S4)
\end{abstract}

Keywords: hepatitis B, Middle East, epidemiology.

The prevalence of hepatitis B virus (HBV) carriage in the Middle East has been reported to vary from $5-18 \% .^{1-4}$ In some regions, however, rates of less than $5 \%$ have been reported, ${ }^{5-7}$ while parts of Saudi Arabia and Egypt have reported rates as high as $28 \%$ and $20 \%$, respectively. ${ }^{8}$

The distribution of HBV in the Middle East is characterised by considerable variability in carrier rates, according to geographical area and community. ${ }^{2}{ }^{39}$ In Jordan, family size and particularly socioeconomic status have been shown to have an important influence on the adult $\mathrm{HBV}$ carrier rate, with the highest rate $(11 \%)$ reported in the lower socioeconomic category and, conversely, the lowest rate (4\%) in the higher category. ${ }^{10}$ In a Saudi Arabian study of children, however, no such relation was found. ${ }^{9}$

GI and Liver Unit, Faculty of Medicine, University of Jordan, Amman, Jordan A U Toukan

Correspondence to: Dr A U Toukan, Chief, Gastroenterology and Liver Gastroenterology and Liver Hospital, PO Box 5192, Amman, Jordan.

\section{Familial transmission patterns of} hepatitis B

Perinatal transmission of $\mathrm{HBV}$ in the Middle East probably contributes only minimally to the HBV carrier population. Thus, in a combined study of four countries in the Middle East, only $21 \%$ of children born to HBsAg positive mothers became HBV carriers. ${ }^{8}$ One factor accounting for this may be the low prevalence of hepatitis $\mathrm{B}$ e antigen (HBeAg) positivity $(13 \%)$ in $\mathrm{HBsAg}$ positive mothers in the region. ${ }^{8}$

Nevertheless, the HBsAg carrier rate seems to peak rapidly between 1 and 2 years of age and then fluctuates around that level during subsequent years. ${ }^{39}$ Exposure to $\mathrm{HBV}$, on the other hand, increases steadily with age. ${ }^{369}$ $\mathrm{HBeAg}$ positivity is most prevalent in children, ${ }^{3}$ probably accounting for the high infectivity of HBV in this age group. Intrafamilial, non-sexual, non-parenteral contact has been emphasised as an important means of virus transmission, ${ }^{11}$ and is the major route of infection among children in the Middle East. $^{3}$ Pronounced familial clustering of HBV carrier children has been seen, such that $34 \%$ of siblings of $\mathrm{HBsAg}$ positive children also carry the virus. ${ }^{3}$ This finding emphasises intrafamilial childhood horizontal transmission as an important means by which HBV endemicity rates are maintained in the Middle East, particularly as age of infection is inversely related to $\mathrm{HBV}$ carrier status. ${ }^{12}$

Significantly, the pattern of infection among adults is similar to that found among children. Thus, $39 \%$ of adult siblings of HBV carriers have also been found to carry HBV, compared with $10 \%$ of their age matched spouses (Table I). (A U Toukan, unpublished data.) As many of these siblings now reside outside the immediate family environment in which they grew up, and many are married with families of their own, it follows that this pattern of infection has probably persisted from childhood rather than followed adulthood exposure to the virus. Such evidence is consistent with the concept that the carrier state that is acquired in childhood persists into adulthood, ${ }^{11}$ and that sexual transmission later in life is less important than childhood sibling contact in maintaining the endemicity of the virus in the area. As persistence of the HBV carrier state predisposes to chronic disease - including hepatocellular carcinoma - in later life, ${ }^{13-15}$ the major disease burden in the area must result from this horizontally acquired infection in early childhood.

TABLE I HBs $A g$ status in siblings and spouses of $H B V$ carriers

\begin{tabular}{llllll}
\hline & \multicolumn{2}{l}{ Total } & & \multicolumn{2}{l}{ HBsAg positive } \\
\cline { 2 - 3 } \cline { 5 - 6 } & Number & $\begin{array}{l}\text { Age }(y) \\
(\text { mean }(S D))\end{array}$ & $\begin{array}{l}\text { Number } \\
(\%)\end{array}$ & $\begin{array}{l}\text { Age }(y) \\
(\text { mean }(S D))\end{array}$ \\
\hline Sibling & 64 & $30(8)$ & & $25+(39)$ & $29(9)^{\star}$ \\
Spouses & 71 & $31(7)$ & & $7 \dagger(10)$ & $39(9)^{\star}$ \\
\hline
\end{tabular}

$t p<0.0005,{ }^{\star} p<0.05$. 
Familial tendency toward liver disease in HBV infection

There is a tendency for alanine aminotransferase (ALT) values to be higher among HBV carriers compared with non-carriers. In 49 HBV carriers, the mean (SD) serum ALT value was 54 (88) IU/l compared with 23 (11) IU// in 75 controls comprising HBsAg negative family members $(p<0.005)$. (A U Toukan, unpublished data.) Moreover, those with raised ALT values tended to cluster in certain families in a fashion similar to the familial clustering of $\mathrm{HBV}$ carriers. Among 26 families studied, $55 \%$ of members with raised ALT values were clustered in only four of the families, while the remainder were scattered among the other 22 families (Table II). The tendency for family clustering of HBV carriers with liver disease has been noted previously, ${ }^{14}$ and may be the result of genetic influences. ${ }^{16}$

\section{Liver disease load due to hepatitis $B$ infection}

Expected rates of acute hepatitis B and chronic liver disease can be derived using clinical outcome data from patients with $\mathrm{HBV}$ infection. ${ }^{12} 1315$ In an area such as the Middle East, where postnatal horizontal transmission predominates, $\mathrm{HBV}$ infection during the first five years of life contributes most to the caseload of chronic liver disease and thus to mortality from hepatitis B. $^{8}$ Infection in later years, on the other hand, contributes less to the chronic liver disease load but more to the number of cases of acute hepatitis. It has been estimated that, in a Middle Eastern birth cohort, $\mathrm{HBV}$ infection might account for up to $2 \%$ of all eventual deaths. ${ }^{8}$

Of 507 patients presenting to a hospital in Jordan with symptoms and signs of acute hepatitis, 169 (33\%) were HBsAg and IgM anti-HBc positive. (A U Toukan, unpublished data.) Fifty six of these 169 patients with acute hepatitis B were followed up for more than six months, and only three $(5 \%)$ remained $\mathrm{HBsAg}$ positive. This suggests that persistent antigenaemia after acute hepatitis B contributes only slightly to the maintenance of $\mathrm{HBV}$ endemicity in Jordan. Among 295 patients with chronic liver disease and 75 patients with hepatocellular carcinoma, HBsAg positivity was found in $97(33 \%)$ and $35(47 \%)$, respectively. (A U Toukan, unpublished data.) There was a male: female predominance of $4: 1$ in chronic liver disease and 6:1 in hepatocellular carcinoma. Only $20 \%$ of these patients were $\mathrm{HBeAg}$ positive, possibly as a result of infection with a precore variant of $\mathrm{HBV}$. A high proportion of HBeAg negative patients with serious liver disease in the Mediterranean area have been found to be infected with these variants, ${ }^{1718}$

TABLE II Distribution of $H B s A g$ carriers with raised $A L T$ values within families

\begin{tabular}{ll}
\hline No of families (\%) & No of members with raised ALT (\%) \\
\hline $4(15)$ & $12(55)$ \\
$22(85)$ & $10(45)$ \\
26 & 22 \\
\hline
\end{tabular}

which do not express the e antigen. Combined chronic infection with $\mathrm{HBV}$ and hepatitis $\mathrm{C}$ virus was found to increase the five year death rate to $89 \%$, compared with $79 \%$ for HBV infection alone. Hepatitis delta virus infection was found in $0-40 \%$ of healthy $\mathrm{HBV}$ carriers and in $15-60 \%$ of $\mathrm{HBs} A g$ positive patients with chronic liver disease in the Middle East and north African region. ${ }^{8}$

It seems, therefore, that HBV makes a substantial contribution to the overall liver disease load and associated high death rates. These findings lend urgency to the implementation of prevention programmes and to the development of treatment modalities for those already carrying the virus or with ongoing liver disease.

\section{Hepatitis B control}

From the data described above, it is evident that, in the Middle East, the population group at greatest risk for $\mathrm{HBV}$ infection and its sequelae are children under 5 years of age. The risk factors for $\mathrm{HBV}$ transmission, particularly within family settings, cannot be easily modified. Consequently, hepatitis $B$ vaccination has been integrated into the national Expanded Programme on Immunisation (EPI) in almost all Middle Eastern Countries (WHO 1995). In Jordan, this was preceded by a demonstration project that elicited data supporting the feasibility of such a programme. This project was carried out over a five year period in a rural/urban population of 60000 people, among whom 3000 newborns a year were vaccinated against hepatitis B at 2, 3, and 6 months of age within the EPI programme. The project provided a vehicle both for training EPI staff and for formulating educational programmes for the recipients. The results showed that EPI information and education activities targeted toward families and health care workers in the vaccination areas led to a hepatitis B vaccine uptake of $98 \%$ in EPI recipients, compared with $68 \%$ in populations not exposed to these activities. This degree of immune coverage set the stage for the eventual expansion of the immunisation programme into the remainder of the country, and vaccinations of all newborns in Jordan started in July 1995.

Cost benefit studies in Jordan have shown that integration of postnatal hepatitis B vaccination into the national EPI programme would result in sevenfold savings in direct health care costs. Such a programme is expected to result in a $57 \%$ decrease in the $\mathrm{HBV}$ carrier rate in any given birth cohort. However, while a $60 \%$ decrease in mortality from $\mathrm{HBV}$ infection is also expected, this reduction will not become apparent until at least 20-30 years later, when the first vaccinated cohorts reach the age at which chronic liver disease is expected to present clinically. Thus, while disease loads may eventually be reduced significantly, a number of limiting factors mean that total eradication of HBV infection is not a realistic prospect in the near future. These limiting factors include poor vaccine acceptance by the target population, lack of prevention of perinatal infection in 
a postnatal immunisation programme, and a poor antibody response to the vaccine in some people. In addition, until sufficient generations of infants have been immunised, there will continue to be large numbers of $\mathrm{HBV}$ carriers and associated cases of liver disease. There is a clear need, therefore, for continued development of effective treatments for patients with chronic hepatitis B and for elimination of the virus in carriers.

1 Skinhøj $\mathrm{P}, \mathrm{Al}-\mathrm{Kassab} \mathrm{S}$. Hepatitis-B antigen in Iraq. Lancet 1973; ii: 1269 .

2 Al-Faleh FZ. Hepatitis B infection in Saudi Arabia. Ann Saudi Med 1988; 8: 474-80.

3 Toukan AU, Sharaiha ZK, Abu-El-Rub OA, et al. The epidemiology of hepatitis $B$ virus among family members in the Middle East. Am $\mathcal{F}$ Epidemiol 1990; 132: 220-32.

4 El-Guneid AM, Gunaid AA, O'Neill AM, Zureikat NI, Coleman JC, Murray-Lyon IM. Prevalence of hepatitis B, $\mathrm{C}$, and D virus markers in Yemeni patients with chronic $\mathrm{C}$, and D virus markers in Yemeni patients
liver disease. $\mathcal{F}$ Med Virol 1993; 40: 330-3.

5 Alkanderi S, Al-Nakib W. Prevalence of HBsAg and antiHBs in Kuwait. F Kuwait Med Assoc 1983; 17: 99-105.
Honderi S, Al-Nakib W. Prevalence of HBs and anti-

6 Nashef L, Thalgi A. Hepatitis B serology among the Palestinian population. Ann Trop Paediatr 1992; 12: 321-5.

7 Bar-Shany S, Green MS, Slepon R, Gilon E. Ethnic differences in the prevalence of hepatitis $B$ surface antigen among Israeli blood donors: changes between 1972 and 1988. Int $\mathcal{F}$ Epidemiol 1991; 20: 271-5.

8 Toukan A, and the Middle East Regional Study Group. Strategy for the control of hepatitis B virus infection in the

9 Al-Faleh FZ, Ayoola EA, Arif M. Seroepidemiology of Al-Faleh FZ, Ayoola EA, Arif M. Seroepidemiology of
hepatitis B virus infection in Saudi Arabian children: a hepatitis B virus infection in Saudi Arabian children: a Infect 1992; 24: 197-206.

10 Toukan A. Hepatitis B virus infection in urban residents of Jordan with particular reference to socioeconomic factors. Trop Gastroenterol 1987; 8: 161-6.

11 Szmuness W, Prince AM, Hirsch RL, Brotman B. Familial clustering of hepatitis B infection. N Engl $\mathcal{F}$ Med 1973; 289: $1162-6$.

12 McMahon BJ, Alward WLM, Hall DB, et al. Acute hepatitis $B$ virus infection: relation of age to the clinical expression of disease and subsequent development of the carrier state. F Infect Dis 1985; 151: 599-603.

13 Beasley RP, Hwang LY, Lin CC, et al. Hepatocellular carcinoma and HBV: a prospective study of 22707 men in noma and HBV: a prospective study
Taiwan. Lancet 1981 ; ii: $1129-33$.

14 Ohbayashi A, Okochi K, Mayumi M. Familial clustering of asymptomatic carriers of Australia antigen and patients with chronic liver disease or primary liver cancer. Gastroenterology 1972; 62: 618-25.

15 Beasley RP. Hepatitis B virus as the etiologic agent in hepatocellular carcinoma: epidemiologic considerations. Hepatology 1982; 2: 21-6S.

16 Thursz MR, Kwiatkowski K, Allsopp CEM, Greenwood BM, Thomas HC, Hill AVS. Association between an MHC Class II allele and clearance of hepatitis B virus in the Gambia. N Engl f Med 1995; 332: 1065-9.

17 Brunetto MR, Stemmlar M, Schödel F, et al. Identification of HBV variants which cannot produce precore derived $\mathrm{HBeAg}$ and may be responsible

18 Carman WF, Jacyna MR, Hadziyannis $S$, et al. Mutation preventing formation of e antigen in patients with chronic HBV infection. Lancet 1989; ii: 588-91.

\section{Discussion}

Gust: In the first of your cost-benefit analyses, you said that only about $10 \%$ of pregnant women were $\mathrm{HBeAg}$ positive, and that is where you would expect the failures in your immunisation programme to occur, and yet you predict that only about $69 \%$ of carriers will be prevented by perinatal immunisation strategies. Normally, one would expect $95 \%$ of babies born to $\mathrm{HBeAg}$ negative mothers to be protected, and some of the babies born to $\mathrm{HBeAg}$ positive mothers, so why are your predicted figures so low?

Toukan: One has to take a worst case scenario when doing a cost-benefit analysis. If compliance is estimated to be around $85 \%$ and vaccine efficacy about the same, that gives an overall protection rate of about $70 \%$.

Hollinger: Does your vaccination course include an extra dose at 12 months, as well as the initial three doses at 2,3 , and 4 months?

Toukan: No. There seems to be enough evidence that vaccination of infants at 2,3 , and 4 months is sufficiently immunogenic to allow protection for at least 10 years. In our demonstration projects, we gave the measles vaccine at 2,3 , and 9 months but, by the third injection, there was an uptake of only 60 or $70 \%$. So delaying the third dose to increase immune levels over a longer period of time was done at the expense of compliance.

Kew: When you calculated the risk of hepatocarcinoma in HBV carriers, HCV carriers and those with $\mathrm{HBV}$ and $\mathrm{HCV}$ together, did you calculate a relative risk for each?

Toukan: No. We estimated the five year mortality by entering patients with viral induced cirrhosis into a five year observation period and calculating the death rate at the end of this time period.

Hollinger: This is a very high five year death rate. Of course, it depends on the stage of their liver disease when they enter the study. There is a big difference in mortality between someone starting with mild chronic hepatitis and someone with cirrhosis or severe chronic active hepatitis, for example.

Toukan: They were matched for liver disease stage before entering the five year follow up period. 